\title{
Creating sustainability: place branding strategies and the emergence of creative milieus in heritage sensitive cities
}

\begin{abstract}
The paper aims at examining the role of particular place branding strategies in the emergence of creative milieus within the cities where a cultural heritage is perceived as being of special importance and pride. The main question is thus of how to appreciate what heritage is working, thereby offering inspiration for people to be creative and open to innovative ideas and practices crucial for sustainable development of a heritagesensitive city. The paper seeks to provide a critical account of the concepts of invented tradition, heritage-sensitive city and urban creative milieu while breaking with the rhetoric of creativity distinguishing the literature which still prevails in the field. It highlights some details concerning the impact of place branding on forming local cultural identity, with a special focus on the role of such identity in the emergence of urban creative milieus. The paper specifies the design of the comparative case studies of the emergence of creative milieus within medium-sized cities of Ivanovo (Russia), Liberec (the Czech Republic), Enschede (the Netherlands) and Tampere (Finland) which were traditionally distinguished by the predominance of the textile industry in the structure of local economy. In this context, it defines strengths and weaknesses of the study that has been made to date.
\end{abstract}

Keywords: heritage-sensitive city, sustainable development, tradition, creative, milieu, place, branding
Volume 2 Issue 5 - 2018

\author{
Mark Kleyman \\ Department of Philosophy, Ivanovo State University of \\ Chemistry and Technology, Russia
}

Correspondence: Mark Kleyman, Department of Philosophy, Ivanovo State University of Chemistry and Technology, Russia, Email mark.kleyman27I2@gmail.com

Received: February 22, 2018 | Published: October 08, 2018

\section{Introduction}

Is there a relationship between a city's past and the ways of its sustainable development? How creative ideas and practices can impact on these processes? The influence of many social, economic and cultural aspects on the emergence of urban creative milieus is a core element of scholarly discussions of the factors that can make a particular city attractive to creative individuals. Yet a sometimes somewhat neglected issue is a role of cultural heritage in these processes. The main research question is thus whether such heritage can be regarded as dogmatic and inflexible, or the conservation of traditions, which are regarded as crucial for sustainable urban development, and the emergence of creative milieus may become complimentary to each other. The aim of this paper is to examine how particular place branding strategies can influence on the emergence of creative milieus within the cities where a cultural heritage is perceived as being of special importance and pride. The main question is thus of how to appreciate what heritage is working, thereby offering inspiration for people to be creative and open to innovative ideas and practices. In contrast, the modernist genre of criticism focuses on what is not working, typically offering cautionary tales about what not to do. In other words, we need to narrate a story about a city's cultural heritage, and such narrative should enable both city's residents and newcomers to work creatively upon drawing the routes of further urban development; at the same time, these routes should become complimentary to city's roots. ${ }^{1}$ As it seems, place branding can be regarded, to a more or lesser extent, as a kind of such narrative.

First, the paper seeks to provide a critical account of the concepts of invented tradition, heritage-sensitive city and urban creative milieu. Second, it intends to highlight some details concerning the impact of place branding on forming local / regional social identity, with a special focus on the role of such identity in the emergence of urban creative milieus. Third, it presents the main details of the ongoing comparative case studies of the emergence of creative milieus within a (possibly) wide range of heritage-sensitive cities. In this regard, the paper identifies strengths and weaknesses of the study that has been made to date.

\section{Theoretical background}

Tradition is often regarded as anything transmitted or handed down from the past to the present ${ }^{2,3}$ and, in this context, it can be considered as a tangible reality which helps resolve everyday problems. In a city's context, tradition is expressed in various forms, such as the legacy of how a city was built in response to past circumstances, the structure of local/regional economy, barriers set up by municipal boundaries, socio-cultural characteristics of local inhabitants, and enclaves and ghettos for religious, ethnic or racial groups. The theoretical framework of this proposal is founded on the concept of the invention of tradition, which was made prominent in the eponymous 1983 book edited by British scholars Eric Hobsbawm \&Terence Ranger. ${ }^{4}$ At the same time, we realize that this concept hides serious ambiguities. For example, it is often not possible (or useful) to distinguish between 'genuine' and recently 'invented' traditions, as both are intrinsic parts of a city's cultural heritage. Yet we suppose that the term 'invented tradition' has some explanatory potential. In terms of this proposal, it enables us to start with an assumption that traditions are social inventions and not some primordial characteristics. As it seems, the cases of heritage-sensitive cities provide a clear evidence of that.

Most often such cities are regarded mainly as places with a set of valuable buildings and cultural landscapes..$^{5}$ At the same time, the term 'heritage' refers, in a broader sense, to events or processes that have a special meaning in group memory. ${ }^{6}$ In this context, one can regard heritage-sensitive cities as places with the special importance of a distinctive tradition expressed, for instance, in art, buildings, and/or a special kind of economic activity. As a consequence, this 
has a special meaning for forming a distinct local/regional identity. Such identity, or, to say more precisely, its inside/outside (us/them) dimensions, may be regarded as a crucial factor that specifies the emergence of the distinctive cultural identity. This assumption is in many respects based on the theoretical concept of social identity complexity ${ }^{7}$ that refers to an individual's subjective representation of the degree of overlap perceived to exist between groups of which a person is simultaneously a member. Given the recognition that urban residents inevitably belong to multiple social groups with multiple corresponding social identities, an important question to be addressed is how individuals combine these group identities when they define their subjective in-group. More specifically, do multiple group memberships lead to more inclusive or less inclusive in-groups, when compared to single group identities? According to Müller, ${ }^{8}$ it is accurate to comprehend a contemporary urban neighborhood as an open system of communication, rather than as an integrated social system of shared meanings and morals, which is embedded in a local context. Societies are nowadays, first of all, communicating societies, networks of mobility, and flows and social communication. Therefore social identity should be understood as a project, whose main objective is active participation in the process of fair and open communication within various spheres of local affairs. Communication itself could (and should) be the main overarching defining characteristic of social identities, which resembles, as Stuart Hall ${ }^{1}$ brilliantly pointed out, 'routes' rather than 'roots'. In this regard, it is possible to distinguish between active and passive borders of social identity. The active border is characterized by numerous channels providing contacts with 'outside' cultures, and thus fosters the emergence of social identity complexity. Under these circumstances tradition underpins adopting and adapting ideas and practices from the 'outer' cultures to a particular city's context. In such a case, cultural heritage can be considered not as somewhat dogmatic and inflexible, but as a factor that fosters the development of innovative practices. On the contrary, the passive border is marked by a communicational impermeability that seduce to the stereotypical labeling, defining and preserving polarity of 'us' and 'them'. In such a case, tradition tends to produce strict individual obedience to commonly shared rules, both formal and informal, without any doubt about their legitimacy. Hence, any alternative worldview, as well as the ways of creating something new, is opposed. Urban neighborhoods become the inflexible guardians of tradition, which is unalterably opposed to every sort of personal and / or group deviation from the socially accepted type. One cannot often avoid that in heritage-sensitive cities which are seen as closed and exclusionary 'fortresses'. This vision is based on the essentialist interpretation of the distinct heritage and forging an identity which is characterized by passive borders.

The problem of how the borders of social identities are established and maintained, is thus gathering greater momentum. In fact, social identity consists of psychology, morality, habits and praxis. In this regard, social climate can be considered as a medium for transmitting and enforcing important social values in the city's everyday life. ${ }^{9}$ These are included in the social goals that particular groups of people (for instance, urban neighborhoods) have to accomplish. ${ }^{10}$ In this context, a distinct moral climate can be regarded as a constituent of social climate within the city. Moral climate includes a set of social attitudes which specify the shared perceptions of what constitutes ethical behavior, and the process of how ethical or moral issues will be dealt. ${ }^{11,12}$ If moral climate within some urban neighborhoods fosters intolerance and even aggressiveness towards any form of 'otherness', such neighborhoods underpin passive borders of closed, nested social identity. On the contrary, in the case when moral climate motivates urban inhabitants to be tolerant and open towards 'outer' cultures, alternative ways of thinking and lifestyles, this inevitably results in the emergence of active borders of social identity (and, then, social identity complexity). In any respect, moral climate (and, in a broader sense, social climate) within urban neighborhoods is considerably impacted by formal and informal knowledge of the genesis, nature and structure of local/regional traditions. Genuine and recently established traditions are thus 'invented' alike in the sense that the knowledge of both is socially constructed and embedded into some master narratives which are crucial for forming a distinctive social identity. In Benedict Anderson's sense, this knowledge is often used for forming 'imagined communities' ${ }^{13}$ and, in this regard, the whole process can be considered as a kind of knowledge management. ${ }^{14-16}$ As it seems, place branding can be regarded, among others, as a way of producing this knowledge. As it seems, these issues are currently gaining unprecedented momentum in today's world, where such narratives are being increasingly producing by means of digital media and global networks. In this context, the analysis of such issues may contribute to the ongoing discourses about relational spaces e.g in social geography ${ }^{17}$ or sociology, ${ }^{18}$ as practices of (collective) construction of spaces are still a sadly neglected research matter, whereas normative models of an 'ideal' city are overemphasized. According to Anholt, ${ }^{19}$ 'a globalised world is a marketplace where country has to compete with country-and region with region, city with city-for its share of attention, of reputation, of spend, of goodwill, of trust'. In this context, city branding is often confused with city marketing. Yet the difference comes from the fact that marketing addresses consumer's wishes and needs and uses them as its guiding principle for the operations of a city or town, whereas in the case of branding a chosen vision, mission and identity plays a crucial role. City branding thus refers to the application of branding techniques to geographical locations in the widest sense of the word. To say more exactly, place branding considerably impacts on creating shared imaginaries for cities. ${ }^{20-22}$ As it seems, this considerably impacts on the emergence of urban creative milieus. As Landry ${ }^{23}$ states, a creative milieu is a place where "face-to-face interaction [among a critical mass of entrepreneurs, intellectuals, social activists, artists, administrators, power brokers or students] creates new ideas, artefacts, products, services and institutions and, as a consequence, contributes to economic success' ${ }^{23,24} \mathrm{At}$ the same time, 'in contrast to the more venerable innovative milieu construct that initially focused on creative interaction among workers and between firms and research institutes to examine innovation and economic competitiveness, members of the creative class seek to imbue creativity in all aspects of their lives. ${ }^{22}$ According to Florida, ${ }^{25,27}$ creative professions differ from all other professions in the fact that they base their work on defining issues, finding their solutions, while employing the existing knowledge in a new and innovative manner. In this context, while a 'weak definition' of creative milieu ${ }^{24}$ requires that unobserved interaction attracts a diverse set of creative people to creative places, a 'strong definition' of creative milieu ${ }^{22-29}$ posits that interaction across the diverse creative domains produces an innovative milieu which increases the dynamism of the local economy. ${ }^{23}$ In this regard, creative economy is defined as the sum of economic activities arising from a highly educated segment of the workforce, which encompasses a wide variety of creative individuals. ${ }^{30}$ In John Howkins's sense, creative economy comprises advertising, architecture, art, crafts, design, fashion, film, music, performing arts, publishing, software, toys and 
games, TV and radio, and video games. Some scholars consider that education industry, including public and private services, is also forming a part of creative economy. There remain, therefore, different definitions of the sector. ${ }^{31}$ At the same time, the attempts to divide all the professions into creative and non-creative inevitably result in a distinct elitism of creative class theory. ${ }^{32}$ According to Peck $^{33}$ the contemporary creativity strategies barely disrupt extant urban policy orthodoxies, based on interlocal competition, place marketing, property-and market-led development, gentrification and normalized socio-spatial inequality. This has the effect of elevating creativity to the status of a new urban imperative. Hence, to overcome the inherent weaknesses of creative class theory and to break with the rhetoric of creativity distinguishing the scholarly literature which still prevails in the field, one can notice that in a summary of research into creativity Michael Mumford suggested that 'creativity involves the production of novel, useful products'. ${ }^{32}$ Creativity can also be defined as the process of producing something that is both original and worthwhile or characterized by originality, expressiveness and a person's imagination (ibid). In this sense, creativity cannot be regarded merely in terms of economic effectiveness and one's professional or, moreover, class affiliation. Creative milieu can thus be considered as a set of formal and informal institutions supporting an individual or a group of people in thinking and acting creatively, regardless of one's professional, social and/or cultural status. In this regard, the issues of social identity complexity play a crucial role in the sustainable development of the city. Therefore, the critical urban theory, ${ }^{34}$ which is rooted back to Henri Lefebvre's claim to the 'right to the city', i.e., a right to change ourselves by changing the city, can provide an alternative theoretical framework for the creativity studies. In this sense, place branding should motivate people in every place (including heritage-sensitive cities) to obtain their right to work creatively upon developing a 'city for people, not for profit'. ${ }^{33}$ The main problem is thus whether it is possible within the frameworks of the neoliberal urban development paradigm which still considerably impacts on the global urban scene. ${ }^{36,39}$

\section{Hypotheses}

As stated above, the starting point of this research project is an attempt to understand the process of the invention of tradition not in regard to the problem of how a particular tradition has been initiated but in terms of producing the knowledge of recent and/or remote past and embedding it into a particular narrative. One may thus suppose that the knowledge of particular tradition which addresses the issues of openness to change, meritocracy, social equality and universalism, lower importance of conservatism and power values and higher tolerance for diversity is crucial for the emergence of social identity complexity. The first basic hypothesis thus states that Place branding which produces the knowledge of tradition as not dogmatic and inflexible, but as a starting point for adapting and adopting new ideas and practices to a city's context has a positive effect on the emergence of urban creative milieus.

In the next step, I address the question of how tradition can be viewed in the heritage-sensitive city's context. On the one hand, it can play a crucial role in maintaining closed, exclusive identity. For instance, one can assert that the cities with the predominance of the textile industry must be developed exclusively as the centers of this mono-industry. In this context, old textile factory building must be used merely for producing fabrics on the basis of using simple technologies. On the contrary, one can find the ways of using this heritage in new ways (for instance, when transforming old factory buildings into a place of developing high-tech industries, educational institutions, or a venue for art performances). In any respect, in increasingly placeless world, when question of urban character and identity gathers unprecedented momentum, ${ }^{40}$ place branding can help heritage-sensitive cities use their unique chance to create their future by using many elements of their past. Stressing the creative potential of these cities is likely a way to avoid 'drawing caricatures' which describe some cities as civic cities and other as bureaucratic or individualist places. ${ }^{41,42}$ In fact, place branding strategies based on these descriptions are accurate to a certain extent, but they do not fully represent the complex relationships between local traditions and their impact on the emergence of urban creative milieus. Therefore, the second hypothesis examines the ways of how a unique city's heritage can be used for the purpose of place branding:

Place branding strategies which put an emphasis on the elements of a city's cultural heritage that can provide 'routes' to their further development, alongside with preserving their historical 'roots' can have a positive effect on the emergence of urban creative milieus.

In this sense, the other aspect of place branding in regard to a heritage-sensitive city's context is practical knowledge of how to narrate the story of its 'roots' and 'routes' to the future. The third hypothesis states that

Place branding strategies, which involve representing many related images of a heritage-sensitive city under a single brand name, can provide an opportunity for individuals and groups from different social and/or professional backgrounds to create and re-invent their city of residence.

One can suppose that addressing the tradition of a single group (for example, textile workers) for the purpose of place branding likely produces exclusive, closed identity of heritage-sensitive city. On the opposite, if we narrate the story about the elements of distinctive cultural heritage which can gather together people of different cultural backgrounds, this can help find the 'routes' to the future and, at the same time, preserve city's 'roots'.

\section{Research methodology}

The project aims to initiate the comparative case studies of the emergence of creative milieus within a (possibly) wide range of heritage-sensitive cities. As Robinson ${ }^{43}$ states, qualitative case studies are particularly well suited to account for the diversity of cities and to gain a comprehensive situative understanding of their distinct context (for instance, a distinct cultural heritage). Rober $t^{44,45}$ suggests that this methodology is well suited to address multifaceted social processes (such as the invention of tradition), particularly when

1. 'how' and 'why' questions are being posed',

2. the investigator has little control over events

3. the focus is on the contemporary phenomenon within real-live context". ${ }^{43}$

In this regard, comparative case studies can help emphasize comparison within and across contexts of several heritage-sensitive cities. ${ }^{41,44}$ According to Robinson, "in relation to urban studies, it has been particularly productive to bring the experiences of different case-study cities into careful conversation with one another in order to reflect critically on extant theory, to raise questions about one city through attending to related dynamics in other contexts, or to point 
to limitations or omissions in existing accounts'.${ }^{46}$ For this purpose, I intend to propose the parameters according to which the comparative framework can be structured as follows:

1. Main characteristics of the distinct place branding strategies in relation to data collected from websites, blogs and official documents.

2. Statistical data on the annual numbers of patents, cultural events and educational mobility (especially in regard to equal access to education of people from different social and cultural backgrounds).

3. Questionnaire survey can be considered as a comparatively easy tool to apply and administer which can yield reliable statistically representative information from a large number of people quite quickly. ${ }^{47}$

To test the effectiveness of the questionnaire, I intend to undertake a pilot survey during the fieldwork visits which will aim to investigate how the respondents perceive and appropriate their cities and how they expect them to be seen (and, in this context, how they evaluate the effectiveness of distinct place branding strategies). I regard these issues as a dependent variable, whereas the level of personal creativity of our respondents is considered as an independent variable. The collected data will be systematically coded and arranged using Excel and SPSS for an analysis. At the same time, I think that the questionnaire should be largely integrated with other methodologies. Based on the research material I expect to provide suggestions for the development of place branding strategies that can foster the emergence of urban creative milieus.

At the same time, I intend to narrow the focus of our investigation when concentrating on the cases of medium-sized cities. Although most attention tends to be drawn to the largest metropolitan urban regions, this is definitely not the category of cities in which most urban inhabitants across Europe, including Russia, live. Of around 260 million Europeans living in city regions with more than 100,000 inhabitants, only 20 percent live in city regions of more than 2.5 million people, while almost half (44 percent) of all urban inhabitants live in city regions of less than 500,000 inhabitants. The latter category of cities can be considered to be 'medium-sized' on a European scale. However, such cities inevitably loose in importance when compared with bigger metropolitan areas, which are usually ranked in higher positions..$^{48}$ It is especially true in the cases of medium-sized specialized cities meaning the cities where a particular kind of activity or economic organization is dominant in the economic sphere. ${ }^{49}$ In such cities the particular kind of economic activity inevitably contributes to the structuring the whole of urban society, including formal and informal institutions that impact on forming social identity. For instance, economic activities which have been inherited from the past can have a special meaning in group memory and be subject of commonly shared pride. In this context, specialized cities can be considered as a subtype of heritage-sensitive cities. Effective place branding strategies should thus combine demonstrating the genuine true value of continuity with evaluating opportunities and allowing problems to be perceived as a challenge in the contemporary world, where only the most 'diverse economies' have a possibility to win. ${ }^{50,51}$ I suppose that the need to re-invent specialized cities for the purpose of making them open to innovative ideas and practices could provide the particular method for narrating the story about their traditions. In this context, place branding strategies should put an emphasis on those elements of local cultural heritage that could strive for multiple and complementary, inclusive and positive social identities.

\section{Discussion}

Thus far the study has been focused on the cases of the cities of Liberec, ${ }^{52}$ Tampere ${ }^{53}$ and Enschede. ${ }^{54}$ These medium-sized specialized cities present the legacies of economies based on the predominance of the textile industry. As the textile industry involves the sections like research, design, development, manufacturing and distribution of textiles, fabrics and clothing, its development can provide two opposite paths of specialized city's development. On the one hand, such cities can transform into big centers of research, and this can foster the emergence of creative milieus. But, on the other hand, textile industry can be based on using simple technologies. In such a case, the traditions of specialized textile cities can provide an obstacle to adopting and adapting creative ideas and practices to a particular city's context. Due to fierce competition from mainly the Far East, the textile production in the case cities came to a halt in the second half of the 20th century. At the same time, unlike Enschede and Tampere, Ivanovo and Liberec present the legacy of the socialist planned economy. Specialized cities under state socialism had a strong support by the government for their development, and the support was mainly due to political reasons. This permitted to support mono-industrial economies until the demise of state socialism at the beginning of the 1990s. In any case, the creative potential of the textile industry should be mobilized to restructure the local mono-industrial economies. Therefore, questions of effective place branding strategies applicable to formerly textile cities now gather unprecedented momentum.

As the research is currently at the preliminary stage, the characteristics of the distinct place branding strategies are being scrutinized by means of a secondary research which includes the analysis of the data collected from multiple sources, such as official documents, websites and blogs. The preliminary results of our study can provide an evidence to suggest that place branding strategies in all case cities stress, in one way or another, the importance of the 'routes' to the future. Overall, Ivanovo is represented as the big university centre of Russia. ${ }^{55}$ The motto of 'Enschede innovates' is widely represented as a sort of a business card bearing the main information about this Dutch city with a total population of around 158,000 inhabitants (The City of Enschede). ${ }^{54} \mathrm{As}$ it seems, one can consider that as a good example of umbrella branding which involves representing many related images of the city under a single brand name. Therefore, it provides an opportunity for individuals and groups from different social and/or professional backgrounds to create and re-invent their city of residence. Tampere is represented as a centre of leading-edge technology, research, education, culture, sports and business (City of Tampere). ${ }^{53}$ A predominantly industrial nature of Liberec is depicted as being interconnected with high-tech industries, such as the glass and jewellery industry, the production and processing of plastics, engineering and processing industries are primarily developed with close ties to the production of cars. It is stressed that the traditional textile industry has lost its dominant position due to the slowdown in recent years (Liberec Region). ${ }^{52}$

It is therefore possible to suppose that place branding strategies under scrutiny aim to search for 'routes' to sustainable development of the case city and, at the same time, show the importance of addressing a city's 'roots'. This can foster the emergence of active borders of multi-dimensional social identity within a city. In this context, the case of Ivanovo is likely to be somewhat different. In regard to this city, place branding often stresses the necessity to preserve a distinct character of 'Russian Manchester'. Ivanovo earned such sobriquet during the $19^{\text {th }}$ century, when it became the leading centre of the 
textile industry in Russia. ${ }^{56}$ It is thus often affirmed that Ivanovo should be developed, first of all, as the 'textile cluster' of Russia. This can be likely understood in a broader context of Russia's political and societal scene. The case of contemporary Russia presents a model of state capitalism featured by mixing the return to everything Soviet in regard to ideology and policies with the widespread capitalism tout court in every sector of public and private life. Such model relies, first of all, upon bureaucratic, top-down manner of government in hierarchies (which is evidently in contrast with the current global trend towards replacing this mode of government by the patterns of governance in networks). In this context, decisions concerning local issues are mostly taken at the national level. As a consequence, such hierarchical model leaves local inhabitants with little capacity for action, and the idea of dependence upon their 'roots' forms the cognitive framework within which the new agenda for urban development is embedded. The fact that Ivanovo is the only case among the cities under scrutiny where no reliable English-language versions of the locally produced websites are available, can also be regarded as a result of such dependence upon the 'roots'. Under these circumstances, the hegemonic traditions of mono-professional neighborhoods maintained by informal institutions, local authorities and central government can hinder the development of place branding strategies aimed to foster the emergence of social identity complexity. The current development of Ivanovo provides a good evidence of that. In the post-Soviet era the crisis of the local mono-structural economy led to high unemployment rates and tremendously deteriorating social conditions. In spite of the improvement of the situation in the mid2000 s, resulted from the rising oil prices and the steady increase of the living standards in Russia as a whole, the current economic situation launches most urban dwellers on a career in low-wage services. At the same time, Putin's persistence in chanting the Soviet mantras, like that about 'the leading role of the working class' (which in the Soviet era provides a legitimization of social exclusion and even extermination of 'class enemies'), has led to maintaining the traditional monoindustrial structure of the local economy. But, unlike in the Soviet era, most of fabrics are produced in numerous small sweatshops, whereas the large factory buildings are turned into the enormous shopping malls. As a result, people are increasingly moving to Moscow to seek for higher paid jobs. ${ }^{57}$

\section{Concluding remarks}

In this paper I have described analytical framework of further research, and therefore this has to be considered merely as a necessary preliminary stage in drawing research design. In the current form the proposal thus has too many problems and limits. First, the proposed conceptualization of a heritage-sensitive city needs critical evaluating. This inevitably raises many questions, such as, for instance: Is it possible to consider specialized cities as a subtype of heritage-sensitive cities? Do they possess the main characteristics of heritage-sensitive cities in general? How the particular manner of place branding can affect the emergence of social identity complexity crucial for the development of urban creative milieus?

Second, thus far I have investigated the emergence of urban creative milieus merely within the boundaries of a particular city. However, cities have increasingly become 'unbound' from various points of view; not only because a multiplicity of cultures are characterizing the urban space, ${ }^{58}$ but also because a break has occurred between the city form and functions and the urban government/governance processes. ${ }^{40}$ Cities are thus extending over larger spaces and are facing new challenges ${ }^{59,60}$ In this content, is it possible to shift our focus from heritage-sensitive cities to heritage-sensitive territories branding?

Third, the four case studies proposed do not still seem to be a part of a 'comparative analysis'. They are just four testing fields for the analysis. I intend to take a look at recent debates on comparative methodologies in order to clarify this point. As my study will be both qualitative and quantitative in nature, the question of forming a robust methodological framework and using valid techniques of collecting and analyzing data is also of a special importance. As comparative case studies are generally strong precisely where statistical methods and formal methodologies are weak, this methodology is well suited to a qualitative research design. ${ }^{61}$ At the same time, there is the need to undertake primary research to be based on more representative and statistically reliable data in order to deepen the insight into the impact of various place branding strategies on the emergence of creative milieus in heritage-sensitive cities. In this context, the research should go beyond using exclusively comparative case study methodology. The empirical study should be ideally based on using several different, yet complementary, research methodologies.

In any case, further research in this field could enhance our understanding of what we can do about fostering sustainable development of heritage-sensitive cities where many common identities will be recognized and mutual differences will be respected.

\section{Acknowledgements}

None.

\section{Conflictof interest}

The author declares that there is no conflict of interest.

\section{References}

1. Hall S. New cultures for old. In: Massey D, Jess P, editors. A place in the world? Places, cultures and globalization. Oxford, UK: Open University/ Oxford University Press; 1995. p. 175-213.

2. Shils E. Tradition. London and Boston: Faber \& Faber; 1981. 38 p.

3. Fajmon B, Vokoun J. Interdisziplinäre Traditionstheorie: Motive und Dimensionen [The interdisciplinary theory of tradition: Motives and dimensions]. Münster: Lit; 2016. 382 p.

4. Hobsbawm EJ, Ranger TO. The invention of tradition. Cambridge: Cambridge University Press; 1983. 324 p.

5. Williamson K. Development and design of heritage sensitive cities strategies for listed buildings and conservation areas. London and New York: Routledge; 2010. 204 p.

6. Lowenthal D. The past is a foreign country. New York: Cambridge University Press; 1985. 489 p.

7. Roccas S, Brewer MG. Social identity complexity. Personality and Social Psychology Review. 2002;6:88-106.

8. Müller K. European civil society conundrum: public spheres, identities and the challenge of politicisation. Central European Journal of International and Security Studies. 2014;8(1):32-55.

9. Bennett JB. Social climate research. Corsini Encyclopedia of Psychology. Wiley Online Library; 2010. 2002 p.

10. Allodi MW. The meaning of social climate of learning environments: Some reasons why we do not care enough about it. Learning Environments Research. 2010;13(2):89-104. 
11. Victor B, Cullen JB. The organizational bases of ethical work climates. Administrative Science Quarterly. 1988;33(1):101-125.

12. Novikov VV. Sotsialnaya psikhologuiya: fenomen i nauka [Social psychology: phenomenon and science]. Moscow: Institute of Psychotherapy. 2003.

13. Anderson B. Imagined communities: Reflections on the origin and spread of nationalism. London: Verso; 1991. 240 p.

14. Abelln A, Oxbrow N. Competing with knowledge: The information professional in the knowledge management age. London: Library Association Publishing; 2001. 288 p.

15. Blair D. Knowledge management: Hype, hope or help? Journal of the American Society for Information Science and Technology. 2002;53(12):1019-1028.

16. Lesser E, Prusak L. Preserving knowledge in an uncertain world. MIT Sloan Management Review. 2001;43(1):101-102.

17. Werlen B. Society, action and space: An alternative human geography. London and New York: Routledge; 1993. 249 p.

18. Giddens A. Runaway world: How globalisation is reshaping our lives London: Profile Books Ltd; 2002.104 p.

19. Anholt S. Some important distinctions in place branding. Place Branding and Public Diplomacy. 2005;1(2):116-121.

20. Löw M. The city as experiential space: The production of shared meaning. International Journal of Urban and Regional Research. 2013;37(3):894-908

21. Pasquinelli S. Competition, cooperation and co-opetition: unfolding the process of inter-territorial Branding. Urban Research and Practice. 2013;6(1):1-19.

22. Hoekstra MS. Governing difference in the city: urban imaginaries and the policy practice of migrant incorporation, Territory, Politics, Governance. 2017;6(3):362-380.

23. Landry C. The creative city: a toolkit for urban innovators. London: Earthscan Publications Ltd; 2000. 31 p.

24. Wojan TR, Lambert DM, Mcgranahan DA. Emoting with their feet: Bohemian attraction to creative milieu. Journal of Economic Geography. 2007;7(6):711-736.

25. Florida R. The rise of the creative class: and how it's transforming work, leisure, community, and everyday life. New York: Basic Books; 2002. 416

26. Florida R. The flight of the creative class: the new global competition for talent. New York: Harper Business; 2005. 296 p.

27. Florida R. The new urban crisis: How our cities are increasing inequality, deepening segregation, and failing the middle class - and what we can do about it. New York: Basic Books; 2017. 336 p.

28. Lee SY, Florida R, Acs ZJ. Creativity and entrepreneurship: a regional analysis of new firm formation. Regional Studies. 2004;38(8):879-891.

29. Stolarick K, Florida R. Creativity, connection and innovation: a study of linkages in the Montreal region. Environment and Planning A 2006;38(10):1799-1817.

30. Florida R. The rise of the creative class revisited. New York: Basic Books; 2012. 4 p.

31. Hesmondhalgh D. The cultural industries. London: Sage; 2002. 22 p.

32. Krätke S. The creative capital of cities: interactive knowledge creation and the urbanization economies of innovation. Malden, MA: Wiley-Blackwell 2011. 260 p.
33. Peck J. Struggling with the creative class. International Journal of Urban and Regional Research. 2005;29(4):740-770.

34. Mumford MD. Where have we been, where are we going? Taking stock in creativity research. Creativity Research Journal. 2003;2-315:107-120.

35. Brenner N, Marcuse P, Mayer M. Cities for people, not for profit critical urban theory and the right to the city. London: Routledge; 2011. 296 p.

36. Lefebvre H. Le droit a la ville. [The right to the city]. Paris: Anthropos; 1968. $166 \mathrm{p}$

37. Harvey D. Limits to capital. London: Verso; 2007. 478 p.

38. Purcell M. The Down-Deep Delight of Democracy. Oxford: WileyBlackwell; 2013. 4 p.

39. Tsur N. A new urban paradigm: Our way of looking at cities needs to be turned inside-out. 2015.

40. Evans B, McDonald F, Rudlin D. Urban identity. London: Routledge. 2011. $179 \mathrm{p}$.

41. Amin A. Regions unbound: towards a new politics of place. Geografiska Annaler. 2004; 86B (1):33-44.

42. Zanon B. Scaling-down and scaling-up processes of territorial governance: cities and regions facing institutional reform and planning challenges. Urban Research and Practice. 2013;6(1):19-39.

43. Robinson J. Cities in a world of cities: the comparative gesture. International Journal of Urban and Regional Research. 2011;35(1):1-23.

44. Robertson KA. Pedestrian streets in Sweden's city centers. Cities. 1991;8(4):301-314.

45. Yin RK. Case study research: Design and methods. 4th edition. Thousand Oaks, CA: Sage; 2009. 101 p.

46. Ward K. Towards a relational comparative approach to the study of cities. Progress in Human Geography. 2010;34(4):471-487.

47. Gillham B. Developing a questionnaire. New York: The Continuum International Publishing Group; 2000. 104 p.

48. Giffinger R, Haindlmaier G, Kramar H. The role of rankings in growing city competition. Urban Research and Practice. 2010;3(3):299-312.

49. Artioli F. The Navy and the city: conflict, cooperation and political competition in the urban governance of Toulon. Urban Research and Practice. 2013;6(1):75-94.

50. Camagni RP. The concept of innovative milieu and its relevance for public policies in European lagging regions. Papers in Regional Science. 2005;74(4):317-340.

51. Eisenschwitz A. Neo-liberalism and the future of place marketing. Place Branding and Public Diplomacy. 2010;6(1):79-86.

52. Liberec Region. Liberec region by numbers 2016. 2017. 24 p.

53. City of Tampere. Information on Tampere. 2017.

54. The City of Enschede. The city. 2017.

55. Ivgoradm. Nash gorod. 2017.

56. Cookson R. A world of Manchesters. Manchester: Casthermen Books 2002. 128 p.

57. Ermolayev MB, Ilchenko AN. Trudovaya Migratsiya V Regione: Modeli Analiza i Prognosirovaniya. [Labour Migration in the Region: Models of Analysis and Forecasting]. Moscow: Finansy i Statistika. 2004.

58. Jacobs J. The city unbound: qualitative approaches to the city. Urban Studies. 1993;30(4/5):827-848 
59. Deas I, Giordano B. Regions, city-regions, identity and institutions building: contemporary experiences of the scalar turn in Italy and England. Journal of Urban Affairs. 2003;25(2):225-246.

60. Janssen LB, Hutton TA. Rethinking the metropolis: reconfiguring the governance structures of the twenty-first century city-region. International Planning Studies. 2011;16(3):201-215.
61. Beermann J. Urban cooperation and climate governance. How German and Indian cities join forces to tackle climate change. Wiesbaden: Springer; 2017. $244 \mathrm{p}$ 